\title{
Analysis of the Impact of High-speed Railway on the Upgrade of Consumption Structure
}

\author{
Zheng Jiang $^{1}$ \\ ${ }^{1}$ School of Economics and Management Beijing Jiaotong University Beijing, China
}

\begin{abstract}
In 2008, with the opening of the Beijing-Tianjin High-speed Railway, China entered an era of rapid development of high-speed railways. The operation of high-speed railways in the past decade has had many effects on the economic development of the surrounding areas. In this paper, the panel data of 9 prefecture-level cities in Fujian Province from 2008 to 2018, the first high-speed railway in China to achieve "city-city connectivity", are analyzed by regression analysis. The results verify that the operation of the highspeed rail has a significant positive effect on the upgrade of the local consumption structure and the actual per capita disposable income and actual per capita GDP that affect residents' consumption.
\end{abstract}

\section{Introduction}

Since the opening of the Shinkansen in Japan on October 1,1964 , the high-speed railway has undergone more than 50 years of development. In 2011, the passenger flow of the Shinkansen in Japan reached 307 million passengers, with a turnover of 8.14 billion person-km and a per capita mileage of $265 \mathrm{~km}$. The success of Japan's high-speed rail has a strong impact on the construction of high-speed rail in Europe, and European countries have also built and put into operation high-speed rail. Since the 1990s, China began to carry out a lot of scientific research and technical research on the basic theory and key technical organizations of high-speed railways. The opening of the Beijing-Tianjin intercity train in 2008 marked the official entry of China into the era of high-speed rail.

The current investment and exports have gradually weakened the role of China's economic growth, and residents' consumption is becoming an important driving force. In 2018, the final contribution rate of consumer spending to GDP growth was $76.2 \%$. Consumption is the main driver of China's economic growth. The role is further consolidated. Therefore, it is meaningful to study the relationship between high-speed rail and urban consumption.

High-speed railways are distinguished from traditional transportation infrastructure by their excellent characteristics such as all-weather, large capacity, high safety factor, low energy consumption, less pollution, high land utilization rate, high punctuality rate, comfort and convenience. Changes in residents 'travel choices have a profound impact on the economy and society. Due to the ratcheting effect of consumption, a city's consumption may be affected by its past consumption, and by the central city that is closely connected to it. On the one hand, the consumption development of the central city may produce a siphon effect, attracting the consumption of surrounding cities. In addition, after a threshold, it may produce an overflow effect, thereby affecting and driving the surrounding consumption. The completion of the highspeed railway has broken the traditional geographical pattern, and this change in geographical pattern will likely have an impact on the consumption pattern.

In the 40 years of reform and opening up, Fujian started from a province with a very backward railway base, and later became the first province in the country to have "city-to-city high-speed rail". Xiamen and Fuzhou, have relatively small cities, which is far from second-tier cities such as Nanjing, and Wuhan, and the city's agglomeration effect is weak. The construction of high-speed rail can accelerate the accumulation of surrounding resource elements and population to the central city to a large extent, and promote the construction of Fuzhou and Xia Zhangquan metropolitan areas. The construction of highspeed rail is also conducive to leading the development of urbanization in the province and stimulating the economic development of surrounding areas.

This article specifically uses the data of 9 prefecturelevel cities in Fujian Province to analyze the impact of the opening of high-speed railways on the upgrading of regional consumption structure.

\section{Literature review}

The issue of the impact of high-speed rail on the economy has been quite controversial. Some scholars believe that high-speed rail improves regional accessibility and forms a corridor economy, thereby promoting the expansion of the market, increasing professionalism and productivity, and thus promoting economic growth. For example, Sasaki believes that the opening of the Shinkansen has a positive correlation with the economic growth of cities along the route[1]. Through research on Spanish high- 
speed rail, Cotmila and other scholars have concluded that high-speed rail has beneficially promoted the division of labor in the industry and promoted economic growth[2][3]. Dai N, Hatoko believes that the opening of the high-speed railway can only play a short-term role in promoting economic growth along the way, and in the long run may inhibit economic growth[4]. Domestic scholar Xueliang Zhang et al. believe that high-speed railways have accelerated urbanization within urban agglomerations, promoted economic links between cities, and promoted regional economic integration[5]. Ling Luo believes that the high-speed railway accelerates the process of new urbanization along the route, strengthens the economic scale of the cities and towns along the route, innovates the urban development model, and reconstructs the urban system along the route[6]. Xiangmei Li believes that the opening of the high-speed railway has increased the strength of interregional economic ties and promoted industrial-population ties[7]. Fengbo Lai believes that high-speed rail is the Granger reason for regional economic development[8]. Yufei Wang believe that after the opening of the high-speed railway, the spillover effect of China's regional economic growth has indeed improved[9]. Some scholars believe that whether the regional economic distribution pattern changed by highspeed rail has an impact on the cities passing through depends on whether the industries of the city have greater advantages because of the opening of high-speed rail, and the temporary impact may not bring permanent changes. Vickerman believes that the evidence that high-speed railways affect regional economic growth is not very clear. At the same time, he believes that high-speed railways are more conducive to central cities and promote the growth of central cities, while marginal cities will decrease[10]. The impact of high-speed rail on the economy has not yet reached a unified conclusion, so it is a useful idea to decompose the power of economic growth and explore the impact of high-speed rail on the consumption structure.

\section{Model design}

\subsection{Index selection}

Most of the data used in this article comes from "Fujian Statistical Yearbook", and some of the data comes from "China City Statistical Yearbook" and "Fuzhou Statistical Yearbook". Due to the completeness of data collection, this article selects the data of 9 prefecture-level cities in Fujian Province from 2008 to 2018. All economic data related to price changes are subject to price reduction based on 2008 to remove price effects. The high-speed rail opening data is manually calculated based on the highspeed rail network high-speed rail site data and high-speed rail opening line data.

For the measurement index of consumption structure, this paper builds the consumption structure index CSI (explained variable) by referring to the consumption structure coefficients proposed by Li Jun, Huang Yuan and Xie Weiyi. As the types of household consumption of urban residents can be divided into eight categories of consumption: food, clothing, housing, household equipment supplies and services, medical care, transportation, education and cultural entertainment services, and miscellaneous goods and services. These types of consumer goods basically reflect the relationship of the national consumption level from low to high. The consumption structure index is an indicator that reflects the consumption structure by using the data of the ratio of these eight types of consumer goods to the total consumption expenditure. However, due to the availability of some data from prefecture-level cities, this article selects four categories of consumer goods data for food, clothing, housing, and other service consumption in Fujian from 2008 to 2018. We know that the higher the consumption of high-level consumer goods, the stronger the residents' consumption power and the higher-end consumption structure. The consumption structure index reflects this feature: the higher the level of the consumption structure, the greater the coefficient, otherwise, the smaller the coefficient. Therefore, its calculation formula is :

$$
C S I=\frac{1}{4}\left[\sum_{i=1}^{4} C_{i}+2 \sum_{i=1}^{3}\left(1-\sum_{n=1}^{i} C_{n}\right)\right]-1
$$

Among them, different subscripts i represent different types of consumer goods (or services), the greater the value of $i$, the higher the level of consumer goods (or services) represented by $\mathrm{Ci}$. It is the proportion of consumer goods in category $\mathrm{i}$ in total consumption expenditure. $\sum_{i=1}^{3}\left(1-\sum_{n=1}^{i} C_{n}\right)$ means that for every higher level of consumption, the corresponding consumption ratio is calculated once more in the index. Through this design approach, the influence of higherlevel consumer goods (or services) consumption has been magnified, making the increase in the level of consumption structure more obvious. In addition, the last item -1 is to introduce positive and negative signs in the index, so that the consumption structure level of a region can be judged more intuitively: if the consumption structure index of a country or region is positive, it means that its consumption structure has reached a relatively developed level The level of consumption of high-level consumer goods is higher. If the consumption structure index is negative, it means that the consumption in these areas is still at a relatively low-end stage. The basic consumer goods as a means of living account for a large proportion of total consumption. Even if the impact of higher-level consumer goods is amplified, it cannot be offset The impact of buying large quantities of low-end consumer goods. From the above formula, we can calculate the consumption structure index of nine prefecture-level cities in Fujian Province, see TABLE 1. We can get some simple conclusions from the calculation results:

Table1. Fujian Province Consumption Structure Index

\begin{tabular}{|c|c|c|c|c|c|c|c|c|c|}
\hline Year & FZ & XM & PT & SM & QZ & ZZ & NP & LY & ND \\
\hline $\mathbf{2 0 0 8}$ & 0.017 & 0.110 & 0.006 & 0.014 & 0.047 & -0.004 & -0.016 & 0.050 & -0.004 \\
\hline $\mathbf{2 0 0 9}$ & 0.057 & 0.071 & 0.032 & 0.029 & 0.076 & -0.010 & -0.009 & 0.086 & 0.030 \\
\hline $\mathbf{2 0 1 0}$ & 0.077 & 0.114 & 0.029 & 0.038 & 0.082 & 0.040 & 0.009 & 0.094 & 0.044 \\
\hline $\mathbf{2 0 1 1}$ & 0.118 & 0.161 & 0.043 & 0.044 & 0.118 & 0.039 & 0.064 & 0.108 & 0.025 \\
\hline $\mathbf{2 0 1 2}$ & 0.128 & 0.170 & 0.065 & 0.070 & 0.146 & 0.071 & 0.071 & 0.126 & 0.024 \\
\hline
\end{tabular}




\begin{tabular}{|l|l|l|l|l|l|l|l|l|l|}
\hline $\mathbf{2 0 1 3}$ & 0.157 & 0.202 & 0.093 & 0.082 & 0.154 & 0.094 & 0.073 & 0.128 & 0.063 \\
\hline $\mathbf{2 0 1 4}$ & 0.146 & 0.163 & 0.133 & 0.118 & 0.148 & 0.117 & 0.105 & 0.104 & 0.095 \\
\hline $\mathbf{2 0 1 5}$ & 0.152 & 0.173 & 0.135 & 0.128 & 0.152 & 0.129 & 0.116 & 0.123 & 0.105 \\
\hline $\mathbf{2 0 1 6}$ & 0.148 & 0.184 & 0.142 & 0.148 & 0.150 & 0.137 & 0.153 & 0.130 & 0.127 \\
\hline $\mathbf{2 0 1 7}$ & 0.144 & 0.190 & 0.116 & 0.146 & 0.151 & 0.129 & 0.146 & 0.132 & 0.115 \\
\hline $\mathbf{2 0 1 8}$ & 0.144 & 0.187 & 0.124 & 0.153 & 0.158 & 0.149 & 0.147 & 0.134 & 0.132 \\
\hline
\end{tabular}

Among them, FZ stands for Fuzhou, XM stands for Xiamen, PT stands for Putian, SM stands for Sanming, QZ stands for Quanzhou, ZZ stands for Zhangzhou, NP stands for Nanping, LY stands for Longyan, ND stands for Ningde. Judging from the consumption structure indexes of all regions in Fujian Province, the consumption structure indexes of all regions in Fujian Province are basically greater than zero. Only Zhangzhou, Nanping and Ningde have negative indexes in 2008-2009, which indicates that Fujian The consumption structure of China is at a relatively high level, and residents 'consumption in services accounts for a large proportion; With the gradual progress and upgrade, the living standards of residents have also been significantly improved. In addition, it can be found that the gap between the consumption structure of other regions in 2008 and that of Xiamen is very obvious, but in 2018 the gap between regions has narrowed significantly.

\subsection{Model building}

This article chooses to use the panel data of various cities in Fujian Province from 2008 to 2018 for modeling. We use OLS estimation to evaluate the impact of the opening of high-speed rail on the consumption structure of prefecture-level cities:

$$
Y_{i t}=\alpha+\beta H S R_{i t}+\delta X_{i t}+\mu_{i}+\varepsilon_{i t}(2)
$$

In model (2), the subscript $\mathrm{i}$ represents different prefecture-level cities, $t$ represents the year, and $Y_{i t}$ is the explanatory variable, which is a measure of the economic development index of city $\mathrm{i}$ in year $\mathrm{t}$, including the consumption structure index CSI, GDP per capita, and per capita Disposable income. $H S R_{i t}$ is a virtual variable for urban high-speed rail to measure whether the local highspeed rail is open, defined as (3):

$$
H S R_{i t}= \begin{cases}1, & \text { The city } i \text { has opened in year } t \\ 0, & \text { No high }- \text { speed rail }\end{cases}
$$

His coefficient is the parameter we are most concerned about and needs to be analyzed, indicating the impact of high-speed rail construction on economic development and consumption structure. If the coefficient $\beta$ is significantly positive, it indicates that the construction and opening of the high-speed rail has a positive impact on the city's economic development and consumption structure, while when it is significantly negative, it indicates that the high-speed rail will hinder the city's economic development. $X_{i t}$ is a set of control variables, which to a certain extent eliminates the endogenous and sequential nature of the model to reduce the setting error of the model. Through Fixed Effects Tests and Hausman test, this article selects individual fixed-effect models for regression, $\mu_{i}$ represents individual fixed effects, and other factors that are ignored in the model and change with the city but not with time, $\varepsilon_{i t}$ are error interference terms.

The description of the classification of the variables of the model is shown in TABLE 2. The data of PGDP and PCDI variables are logarithmic data (which can reduce the probability of multiple collinearity and heteroscedasticity to a certain extent, and can increase the stationarity of the sequence).

Table2. Explanation of each variable setting

\begin{tabular}{|c|c|c|}
\hline Variable & Representation & Meaning \\
\hline \multirow{2}{*}{$\begin{array}{c}\text { Explained } \\
\text { variable }\end{array}$} & CSI & Consumption structure measure \\
\cline { 2 - 3 } & PGDP & Real GDP per capita (yuan) by city \\
\cline { 2 - 3 } & PCDI & $\begin{array}{c}\text { Disposable income per capita by city } \\
\text { (yuan) }\end{array}$ \\
\hline $\begin{array}{c}\text { High-speed } \\
\text { rail opening } \\
\text { variables }\end{array}$ & HSR & $\begin{array}{c}\text { High-speed rail factor, the value of high- } \\
\text { speed rail opening was 1, otherwise it was } 0\end{array}$ \\
\hline \multirow{2}{*}{$\begin{array}{c}\text { Control } \\
\text { variable }\end{array}$} & $\mathrm{X} 1$ & $\begin{array}{c}\text { Government scale (government fiscal } \\
\text { general budget expenditure / GDP) }\end{array}$ \\
\cline { 2 - 3 } & $\mathrm{X} 2$ & $\begin{array}{c}\text { Advanced industry, ratio of tertiary industry } \\
\text { to secondary industry }\end{array}$ \\
\hline
\end{tabular}

The descriptive statistics of each variable are shown in TABLE 3.

Table3. Variable descriptive statistics

\begin{tabular}{|c|c|c|c|c|c|}
\hline Variable & Obs. & Mean & Std. Dev. & Min & Max \\
\hline CSI & 99 & 0.101075 & 0.053319 & -0.01579 & 0.202437 \\
\hline LNPGDP & 99 & 10.15882 & 0.270576 & 9.712496 & 10.95874 \\
\hline LNPCDI & 99 & 10.03582 & 0.259265 & 9.504935 & 10.67659 \\
\hline $\boldsymbol{H S R}$ & 99 & 0.656566 & 0.477272 & 0 & 1 \\
\hline $\boldsymbol{X} \boldsymbol{1}$ & 99 & 0.262231 & 0.12168 & 0.068053 & 0.532018 \\
\hline $\boldsymbol{X} \mathbf{2}$ & 99 & 0.805593 & 0.215962 & 0.547159 & 1.435002 \\
\hline
\end{tabular}

\subsection{Stability test}

Table4. Data stationarity test

\begin{tabular}{|c|c|c|c|}
\hline sequence & method & prob & Stationarity \\
\hline $\boldsymbol{C S I}$ & LLC & 0.0000 & smooth \\
\hline LNPGDP & LLC & 0.0000 & smooth \\
\hline LNPCDI & LLC & 0.0240 & smooth \\
\hline $\boldsymbol{X} \boldsymbol{1}$ & LLC & 0.0000 & smooth \\
\hline $\boldsymbol{X} \boldsymbol{2}$ & LLC & 0.0001 & smooth \\
\hline
\end{tabular}

In order to prevent the occurrence of "pseudo regression", it is necessary to test the stability of the data. For panel data, the unit root test is required. In this paper, the same root unit root LLC test is used. If the null hypothesis that there is a unit root is rejected in the test (that is, Prob <0.1), the sequence is considered stable. From the results of the stationarity test in TABLE 4, we can see that CSI, X1, and X2 all passed the stationarity test, and PGDP and PCDI also passed the stationarity test after taking the logarithm.

\section{Empirical results and analysis}

From the perspective of economic growth and consumption structure upgrade, we use individual fixed- 
effects models to estimate OLS regressions on the three explanatory variables of local consumption structure index, real GDP per capita, and per capita disposable income. The impact of the volume and speed of the economic development of 9 prefecture-level cities in the province. The panel regression results are shown in TABLE 5.

Table5. The regression results

\begin{tabular}{|c|c|c|c|}
\hline variable & $\begin{array}{l}\text { (1) } \\
\text { CSI }\end{array}$ & $\begin{array}{c}\text { (2) } \\
\text { LNPGDP }\end{array}$ & $\begin{array}{c}\text { (3) } \\
\text { LNPCDI }\end{array}$ \\
\hline \multicolumn{4}{|c|}{ panel A: No control variables } \\
\hline HSR & $\begin{array}{c}0.081203 * * * \\
(0.008438)\end{array}$ & $\begin{array}{c}0.639985^{* * * *} \\
(0.068851)\end{array}$ & $\begin{array}{c}0.345779 * * * \\
(0.033964)\end{array}$ \\
\hline Constant & $\begin{array}{c}0.047759 * * * \\
(0.006496)\end{array}$ & $\begin{array}{c}10.43001 * * * \\
(0.053006)\end{array}$ & $\begin{array}{c}9.808795^{* * *} * \\
(0.026148)\end{array}$ \\
\hline$R$-squared & 0.636094 & 0.639080 & 0.750631 \\
\hline \multicolumn{4}{|c|}{ panel B: Add control variables } \\
\hline$H S R$ & $\begin{array}{c}0.022623 * * * \\
(0.006571)\end{array}$ & $\begin{array}{c}0.112848 * * * \\
(0.041086)\end{array}$ & $\begin{array}{c}0.085524 * * * \\
(0.019044)\end{array}$ \\
\hline$X 1$ & $\begin{array}{c}0.330425^{* * * *} \\
(0.024686)\end{array}$ & $\begin{array}{c}2.948989 * * * \\
(0.154365)\end{array}$ & $\begin{array}{c}1.435893 * * * \\
(0.071551)\end{array}$ \\
\hline$X 2$ & $\begin{array}{c}-0.082619 * * * \\
(0.020592)\end{array}$ & $\begin{array}{c}-0.491569 * * * \\
(0.128760)\end{array}$ & $\begin{array}{l}-0.035064 \\
(0.059683)\end{array}$ \\
\hline Constant & $\begin{array}{c}0.066131 * * * \\
(0.016228)\end{array}$ & $\begin{array}{c}10.39880^{* * * *} \\
(0.101471)\end{array}$ & $\begin{array}{c}9.631381 * * * \\
(0.047034)\end{array}$ \\
\hline$R$-squared & 0.881151 & 0.930780 & 0.957774 \\
\hline
\end{tabular}

From the estimation results in TABLE 5, whether or not the control variable is added, the high-speed rail factor coefficients are positive, and the high-speed rail effect coefficients of the three models are respectively significant at $1 \%$.

Model (1) uses the consumption structure index CSI as the dependent variable. Without controlling other conditions, the impact of whether the high-speed rail was opened on the consumption structure index was significant at a $1 \%$ significance level, with a coefficient of 0.0812 , adding government scale and industrial advanced After changing the control variables, the coefficient becomes 0.0226 , which indicates that the opening of the high-speed rail has a significant positive effect on the upgrade of the consumption structure of the corresponding region, that is, it effectively promotes the upgrade of the consumption structure of the corresponding prefecture-level city, and the sign and significance of the coefficient Whether it has changed after basic regression or adding other control variables, the conclusion is relatively robust. At the same time, after controlling the local government's impact on the economy, the opening of the high-speed rail has shown a positive impact on consumption, indicating that the government has also played an important role in boosting the economy and increasing income. After the consumption effect is removed, the connection between the local and external economies, that is, the opening of the high-speed rail, has a positive effect on the upgrading of the local consumption structure. The value of the industrial advanced coefficient is negative, indicating that the adjustment of the industrial structure has no significant positive effect on the upgrading of the local residents' consumption structure. The reason may be caused by the existing good industrial structure and consumption habits of the residents. In addition, from TABLE 1, it can be seen that the consumption structure of various cities in Fujian Province is already at a high level, so it has an impact on the upgrade of the consumption structure Not significant.

Model (2) uses the logarithm of real GDP per capita as the dependent variable. Without controlling other conditions, the impact of whether the HSR was opened on the actual GDP per capita was significant at a $1 \%$ significance level. Adding control variables excludes other After the factors influencing per capita GDP, the parameters of the high-speed rail factor are still positive, which indicates that the opening of high-speed rail has a significant positive effect on the per capita GDP development level of the corresponding region, that is, it effectively promotes the economic growth of the corresponding prefecture-level city.

The dependent variable of model (3) is the logarithm of actual per capita disposable income. Without controlling other conditions, the impact of whether highspeed rail was opened in that year on the actual per capita disposable income is significant at a $1 \%$ significance level, with a coefficient of 0.3458 . After adding the control variables of government scale and industrial advancement, the coefficient became 0.0855 , which was a significant drop. It is also found that the coefficient of the influence of government scale on actual per capita disposable income in the control variable is 1.4359 , indicating that government expenditure has a very significant positive effect on the increase in actual per capita disposable income. The regression results of industrial advanced control variables are not significant, indicating that although the high-speed railway has a positive effect on the increase in per capita disposable income, it has not significantly increased the actual per capita disposable income. On the one hand, it may be due to overall macroeconomic growth The level is in a gradual slowing trend. On the one hand, the economic effects brought by the construction of high-speed rail are long-term, and there is a certain lag effect. Many prefecture-level cities have only one or two years to open high-speed rail, so they also have Failure to manifest a significant positive effect.

\section{Conclusion}

This paper verifies the impact of high-speed rail on the upgrading of the consumption structure of regional residents through panel data regression analysis of the first prefecture-level cities in Fujian Province from 2008 to 2018 in China. In terms of measurement methods, this paper uses traditional panel data methods. In addition to studying the consumption structure, it also studies the dependent variables such as actual per capita disposable income and actual per capita GDP that affect residents' consumption to ensure that the results are stable and reliable.

The research results show that: from the perspective of 
consumption structure index data, the consumption structure of Fujian Province itself is already at a relatively high level. Moreover, the opening of the high-speed rail has a promoting effect on the upgrading of the local consumption structure. The study found that the opening of the high-speed rail has promoted the convergence of the consumption structure among regions. The research on real per capita disposable income and real per capita GDP also proves that the opening of high-speed rail has a significant positive effect on the economic development and consumption upgrade of the corresponding regions.

The effects of high-speed rail construction on economic growth can be divided into direct effects and indirect effects. Direct effects refer to the direct pull of high-speed rail construction on investment. At the same time, high-speed rail is a large-scale long-term project that involves many related industries and further produces a multiplier effect. Enhanced the promotion of economic growth; the indirect effect is more abundant and complicated. On the basis of improving regional accessibility, he reduced the cost of intercity transportation and transactions, broke the market segmentation, helped the market scale expansion, and accelerated the labor and capital capital. And the flow of resource resources such as information flow among regions, which has the effect of factor integration, makes the market division of labor more effective, improves market efficiency, and produces economic spillover effects to further promote economic growth. In addition, the co-urbanization effect of high-speed rail also promotes exchange and Communication, especially the agglomeration of personnel in technical positions such as $\mathrm{R} \& \mathrm{D}$, can bring about knowledge spillover effect, generate innovation agglomeration, encourage the promotion of the development of tertiary industries such as high-tech and the transformation and upgrading of industrial structure, and comprehensively promote the region in many aspects and at various levels Economic growth. In the end, the opening of the high-speed railway has brought stronger connections between cities, and its diffusion effect has improved the imbalance of the level of economic development in China to a certain extent.

The impact of high-speed rail on regional economic development and consumption structure upgrade is multilevel and multi-faceted. Although the operation of highspeed rail will bring positive effects such as urbanization effect, economic agglomeration effect and diffusion effect, it may also have certain negative effects. For example, a certain degree of siphon effect. Since this article is a study of all nine prefecture-level cities where high-speed rail is opened in Fujian Province, the impact of the siphon effect has not been analyzed separately, but we cannot ignore the negative impact of high-speed rail on small and mediumsized cities. It is well known that the opportunity of highspeed rail is not a "generalized system of benefits", and it will definitely cause uneven development. Then the focus is on the reform policy of entrepreneurs and government. Therefore, we must scientifically formulate development plans, absorb capital, attract talents, give full play to local advantages, develop local characteristic industries, strengthen cooperation and exchanges in surrounding cities, and introduce relevant entrepreneurial policies to benefit the people. And the government should encourage entrepreneurship, encourage intellectuals to work locally, protect people's livelihood, solve the education and medical problems of children with foreign registration, and handle social security issues. It is not just big cities that have developed in the context of the high-speed rail economy.

\section{Acknowledgment}

First of all, I would like to thank my supervisor Xu Yang for the guidance in the paper, and also especially thank my friends for their encouragement to complete the paper successfully. Finally, I also want to thank my parents for their continuous stand by.

\section{References}

1. Komei Sasaki,Tadahiro Ohashi,Asao Ando. Highspeed rail transit impact on regional systems: does the Shinkansen contribute to dispersion?[J]. SpringerVerlag,1997,31(1).

2. Guineng Chen,João de Abreu e Silva. Estimating the Provincial Economic Impacts of High-speed Rail in Spain: An Application of Structural Equation Modeling[J]. Elsevier Ltd,2014,111.

3. Guineng Chen,João de Abreu e Silva. Using Dynamic Simultaneous-equation Model to Estimate the Regional Impacts of High-speed Rail in Spain[J]. Elsevier B.V.,2015,10.

4. Dai Nakagawa,Masatoshi Hatoko. Reevaluation of Japanese high-speed rail construction[J]. Elsevier Ltd,2006,14(2).

5. Xueliang Zhang, Qingkai Nie. Construction of highspeed railway and integrated development of regional economy in China [J]. Modern City Research, 2010, 25(06): 7-10.

6. Ling Luo. The influence of high-speed railway on the development of cities and towns along the line [J]. Journal of Southwest University for Nationalities (Humanities and Social Sciences Edition), 2013, 34(05):109-113

7. Xiangmei Li, Yayao Liu, Liping Cao. Research on the influence of high-speed railway construction on population mobility space [J]. China Population-Resources and Environment, 2014,24(06):140-147.

8. Fengbo Lai, Chunmei Liu, Chaohe Rong. The effect of high-speed railway on regional economic development and empirical test[J]. Dongyue Lunzheng, 2016, 37(06): 120-127.

9. Yufei Wang, Pengfei Ni. Economic growth spillover and regional space optimization under the influence of high-speed railway[J]. China Industrial Economy, 2016(02): 21-36.

10. Roger Vickerman. High-speed rail in Europe: experience and issues for future development[J]. Springer-Verlag,1997,31(1). 